\title{
Daylight Simulation and Compliance: Reliability of Climate Data Solar Radiation Models
}

\author{
Eleonora Brembilla ${ }^{1}$, John Mardaljevic ${ }^{1}$, Anastasia Mylona ${ }^{2}$ \\ ${ }^{1}$ Loughborough University, Loughborough, UK \\ ${ }^{2}$ Chartered Institution of Building Services Engineers, London, UK
}

\begin{abstract}
This paper investigated the uncertainty introduced in Climate-Based Daylight Modelling (CBDM) by two solar radiation and one luminous efficacy models, chosen among those often found in Building Performance Simulation (BPS) tools. Analyses were carried out for two locations, Camborne, UK, and Sonnblick, Austria. Irradiances and CBDM metrics were found to be more accurately predicted by the model used for IWEC climate files, as such model can be optimised for each specific location. The model used within CIBSE climate files was found to be less accurate. In both cases, the direct component prediction exhibited significant errors.
\end{abstract}

\section{Introduction}

Building Performance Simulation (BPS) makes extensive use of climate files to represent boundary conditions when evaluating building designs. The original scope of these files was to represent typical environmental conditions in a single year, for use in energy performance analysis (Barnaby and Crawley, 2011). For any location, a so-called Typical Meteorological Year (TMY) can be constructed by collating the most representative months, usually selected from a dataset of 10-15 years (Wilcox and Marion, 2008).

A number of additional evaluations - including daylighting - started utilising climate files to represent the external environment. For CBDM, direct normal irradiance and diffuse horizontal irradiance are usually required to recreate the luminous sky distribution at each time step. One of the most widespread climate file formats, the Energy Plus Weather (EPW), contains both sets of three irradiance and illuminance components (global and diffuse horizontal, direct normal). However, these quantities are very seldom measured directly. For example, in all CIBSE and ASHRAE climate datasets they are derived from cloud cover and other weather variables through the use of solar radiation models.

The present paper analyses in depth how solar radiation models are implemented in ASHRAE International Weather for Energy Calculations (IWEC) and
CIBSE Test Reference Years (TRY) climate files, and what are the consequences for CBDM evaluations and metrics. Previously, Copper and Sproul (2013) investigated the effect of changing solar radiation models in building energy modelling for Australian locations. A few papers investigated the effect on CBDM metrics of using standard climate files from different sources (Iversen et al., 2013; Bellia et al., 2015), although none of them looked more deeply at the difference in solar radiation models implemented in those datasets.

More details on the empirical models applied for the creation of CIBSE and IWEC files are presented below and illustrated in Figure 1. Please refer to the Nomenclature section at the end of the paper for an explanation of the acronyms.

\section{CIBSE Climate Files}

CIBSE offers typical, extreme and future climate files for 14 British locations (CIBSE, 2016). The typical years are called TRY but they should not be confused with the American TRYs, which are Actual Meteorological Years (AMY) selected for being characterised by average weather conditions (Barnaby and Crawley, 2011). CIBSE TRYs can be compared to American TMYs, i.e. years created by collating 12 representative months selected from a wider dataset, using the Finkelstein-Schafer (FS) statistics (Finkelstein and Schafer, 1971). The weather variable weights are assigned following the ISO method (Eames et al., 2016). Irradiance quantities are derived from Cloud Cover data - recorded by the UK Met Office at a large number of weather stations - using the Cloud-Radiation Model (CRM) (Muneer, 2004). The CRM relies on the Kasten-Czeplak (Kasten and Czeplak, 1980) model to derive both global and diffuse horizontal irradiance, and on the Perez luminous efficacy model to derive illuminance components (Perez et al., 1990).

\section{ASHRAE IWEC Files}

The EnergyPlus website (DOE, nd) provides IWEC files for locations out of the US and Canada. There exists also a larger dataset of IWEC2 files for worldwide locations (Huang et al., 2014), but that was not evaluated in this study. The methodology followed 
CIBSE TRY

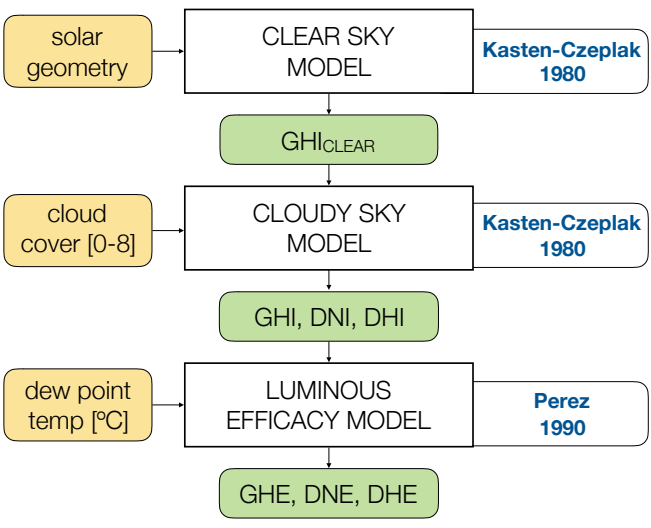

ASHRAE IWEC

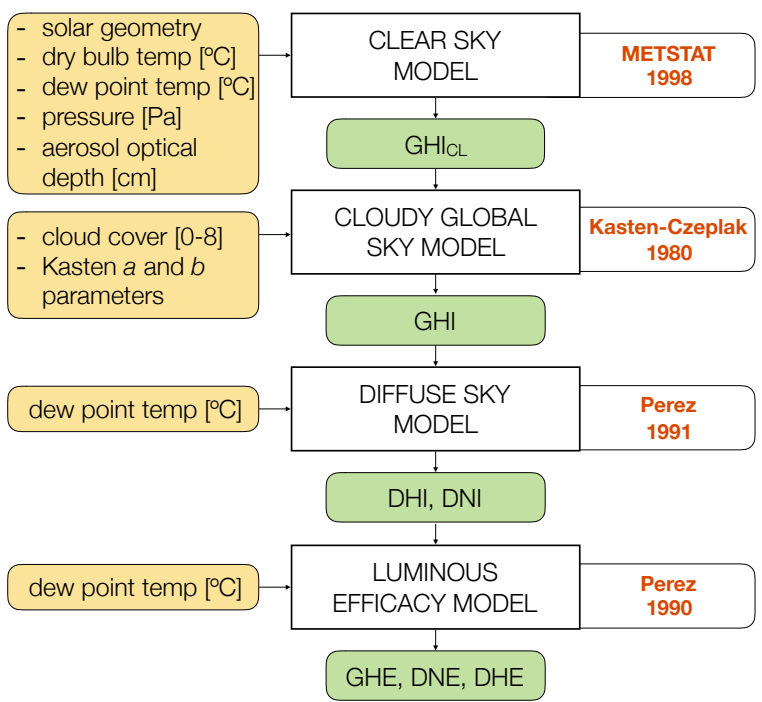

Figure 1: Flowcharts illustrating the sequence of empirical models applied in CIBSE (left) and IWEC (right) files to derive irradiance and illuminance quantities.

to produce IWEC files is meticulously described by Thevenard and Brunger (2001). Similarly to CIBSE files, the creation of representative years uses FS statistics, but more weather variables are considered in the selection process and they are given different weights (Thevenard and Brunger, 2002a).

The procedure to derive solar irradiance is more complex than the one used for CIBSE files. At first, the METSTAT clear sky model (Maxwell, 1998) is used to derive global horizontal irradiance under clear sky conditions. This requires several input variables, as specified in Figure 1. The clear sky global horizontal irradiance $\left(\mathrm{GHI}_{\mathrm{CL}}\right)$ is then used in the KastenCzeplak cloudy model, in conjunction with cloud cover data. The fitting parameters $a$ and $b$ contained in the Kasten-Czeplak formulation (Eq. 1) are optimised at each location, in order to minimise errors when comparing modelled data against daily radiation historical records from the World Radiation Data Center (WRDC) (Thevenard and Brunger, 2002b). The Kasten-Czeplak cloudy model can be formulated as:

$$
\mathrm{GHI}=\mathrm{GHI}_{\mathrm{CL}} \times\left(1-a \times C C^{b}\right)
$$

where:

GHI is Global Horizontal Irradiance;

$\mathrm{GHI}_{\mathrm{CL}}$ is Global Horizontal Irradiance for clear sky; $\mathrm{CC}$ is Cloud Cover;

$a$ and $b$ are the Kasten site-dependent coefficients.

The diffuse and direct parts of global irradiance are then computed with the Perez DIRINT model (Perez et al., 1991). The conversion from irradiance to illuminance is performed via another model by Perez et al. (1990), the same used for CIBSE files.

\section{Methods}

The main scope of this paper was to evaluate the empirical models used to derive irradiance and illuminance in CIBSE standard climate files and in IWEC files, and to quantify the uncertainty in CBDM results due to these solar radiation models.

Two locations were used for the analysis: (i) Camborne, UK, characterised by a warm temperate climate (Cfb as per Köppen-Geiger classification); and (ii) Sonnblick, Austria, characterised by a polar tundra climate (ET as per Köppen-Geiger classification). These two locations were chosen among the available weather stations within the Baseline Surface Radiation Network (BSRN). The BSRN records global horizontal, direct normal and diffuse horizontal irradiance with high grade measuring instruments, at 1 minute time step; it was specifically set up to provide reference datasets for solar radiation model validation (Ohmura et al., 1998). Data from 2016 were selected for the analysis, as for this year it was possible to retrieve almost-complete data series from all the databases used for the analysis, with a maximum of $4.2 \%$ of missing data.

For both locations, the following comparisons were investigated (see Nomenclature at the end of the paper):

1. CRM modelled from $\mathrm{CC}$ against BSRN measured (GHI, DNI, DHI);

2. IWEC modelled from $\mathrm{CC}$ against BSRN measured (GHI, DNI, DHI);

3. Perez modelled from GHI against PHE (Public Health England) measured (GHE, only for Camborne);

4. CBDM interior illuminances (total and direct) ob- 
tained by using irradiances from CRM, IWEC and BSRN measured;

5. CBDM metrics calculated from the illuminance profiles obtained in step 4.

Cloud cover data and other weather parameters necessary for the CRM and IWEC models were retrieved from two different sources. For Camborne, hourly data provided by the Met Office were used (Met Office, 2012). For Sonnblick, data could be found in the Integrated Surface Database (ISD) (NOAA, nd); temperature and pressure data were available at hourly time steps, whereas cloud cover was recorded every three hours and a linear interpolation was therefore performed to derive hourly time series.

As explained in the Introduction, the IWEC model includes an optimisation of Kasten's parameters dependent on the location. Such optimisation was carried out by reducing $\mathrm{MBE}$ and RMSE when comparing results from the IWEC model with BSRN measured data. For Camborne, the parameters used in this work were $a=0.74$ and $b=5.0$; for Sonnblick, they were $a=0.56$ and $b=2.1$.

Illuminance data used to test the Perez luminous efficacy model were provided by $\mathrm{PHE}$, which records global horizontal illuminance at Camborne weather station and other eight British locations (PHE, nd). BSRN measured irradiance values and Met Office measured dew point temperatures were used as input for the model. For solar altitudes lower than $2.5^{\circ}$, a constant diffuse luminous efficacy of $120 \mathrm{~lm} / \mathrm{W}$ was applied, as suggested by CIBSE (2015).

The CBDM analysis was performed on a case study classroom available online for download (cit. removed for blind review). Figure 2 shows the model exterior and the interior plan view, with the contour of the working plane in red. The room internal dimensions are $11.2 \mathrm{~m} \mathrm{x} 7.9 \mathrm{~m}$, and the height is $3 \mathrm{~m}$. The space is side-lit by a curtain-wall window $(\mathrm{WWR}=72 \%)$ oriented towards South; the interior surfaces were assigned standard reflectance values $(20 \%$ for the floor and external ground plane, $50 \%$ for walls, and $70 \%$ for the ceiling); furniture was not included in the simulation.

To test the different solar radiation models, three .wea files were created from the following direct normal and diffuse horizontal irradiance time series: hourly averaged BSRN measured data; cloud cover-derived data via the CRM; and data derived from the IWEC model. In all cases, the luminous efficacy model that allows conversion from irradiance to illuminance was the Perez model (Perez et al., 1990), applied directly within the Radiance simulation system (Larson et al., 1998). Similarly, the sky luminance distribution model adopted for all simulations was the Perez All-Weather model (Perez et al., 1993), coded within the Radiance gendaymtx command. Hence, the isolated influence of the climate files' solar radi- ation models on CBDM illuminance results could be evaluated.

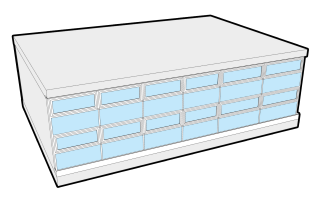

(a)

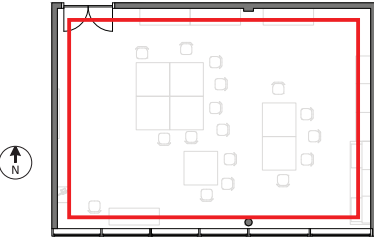

(b)
Figure 2: Exterior view (a) and interior plan view (b) of the classroom model used as case study for $C B D M$ evaluations.

CBDM metrics - calculated from the illuminance profiles obtained as explained before - were also evaluated, to understand whether differences in solar radiation models affect them. Metrics were chosen among those that are commonly required by daylight standards and guidelines (Education Funding Agency, 2014; US Green Building Council (USGBC), 2013) and those used for conservation purposes, namely:

- Daylight Autonomy (DA), 300 lx threshold;

- Useful Daylight Illuminance (UDI), UDI-s: 100300 lx thresholds, UDI-a: 300-3000 lx thresholds;

- Total Annual Illuminance (TAI), in klx hrs;

- Annual Sunlight Exposure (ASE), 1000 lx and 250 hrs thresholds.

Blinds were not included in the model, and an 8 a.m. to 6 p.m. occupancy schedule was considered.

\section{Results}

The results obtained by testing CRM and IWEC models against BSRN measurements are presented first, followed by the analysis of annual illuminance profiles and CBDM metrics.

\section{Solar Radiation Models}

The first set of results came from the comparison between BSRN measured irradiances and irradiance values modelled with either the CRM or IWEC model. The CRM was found to significantly underestimate irradiance values, and the direct normal component in particular. The IWEC model was characterised by smaller errors, which was expected as Kasten's parameters were optimised to reduce such errors. However, clear sky predictions - not dependent by Kasten's cloudy sky parameters - were also found to be more accurate than those obtained by the CRM. The clear sky model inserted within the IWEC method is indeed more complex than the one used within the CRM, and this could explain the better performance. Figures 3 and 4 show the linear regression analysis performed for Sonnblick data. The former Figure compares BSRN measured irradiances with CRM modelled irradiances; none of the three components 
$\mathrm{GHI}$

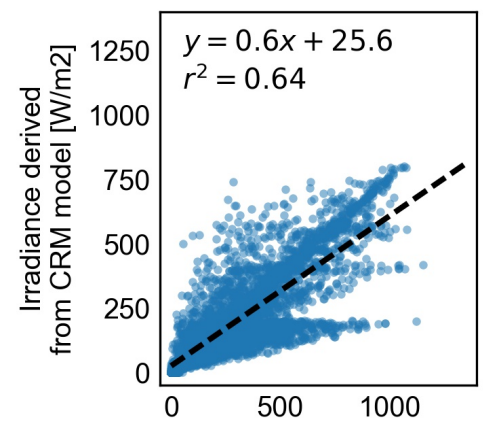

BSRN measurements [W/m2]
DNI

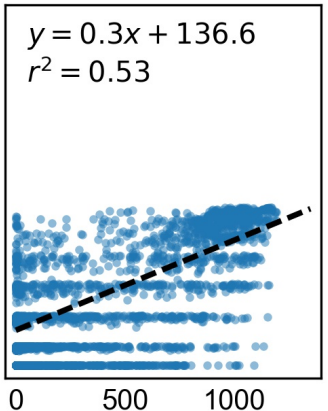

BSRN measurements [W/m2]
$\mathrm{DHI}$

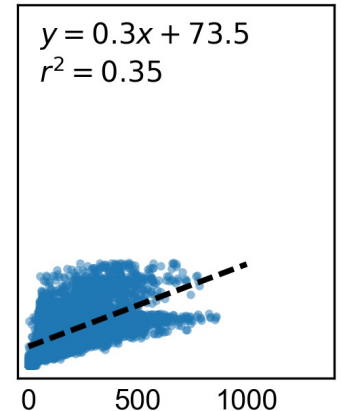

BSRN measurements [W/m2]

Figure 3: Linear regression analysis for Sonnblick data, comparing BSRN measured irradiance with CRM-modelled irradiance. The three irradiance components (global horizontal, direct normal and diffuse horizontal) are shown. All values equal to zero were not considered in the analysis.
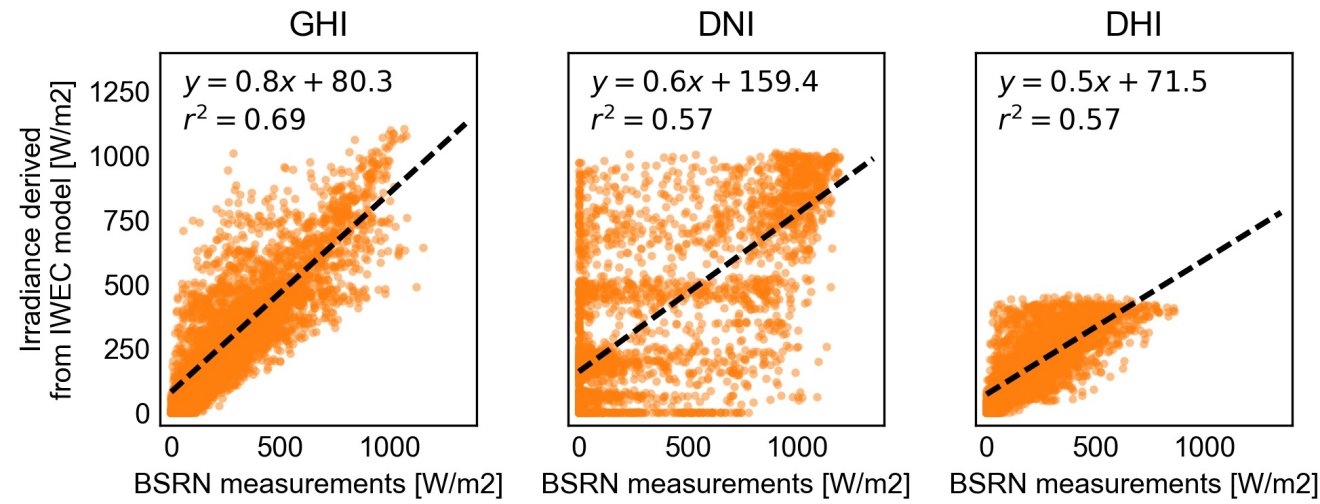

Figure 4: Linear regression analysis for Sonnblick data, comparing BSRN measured irradiance with IWEC-modelled irradiance. The three irradiance components (global horizontal, direct normal and diffuse horizontal) are shown. All values equal to zero were not considered in the analysis.
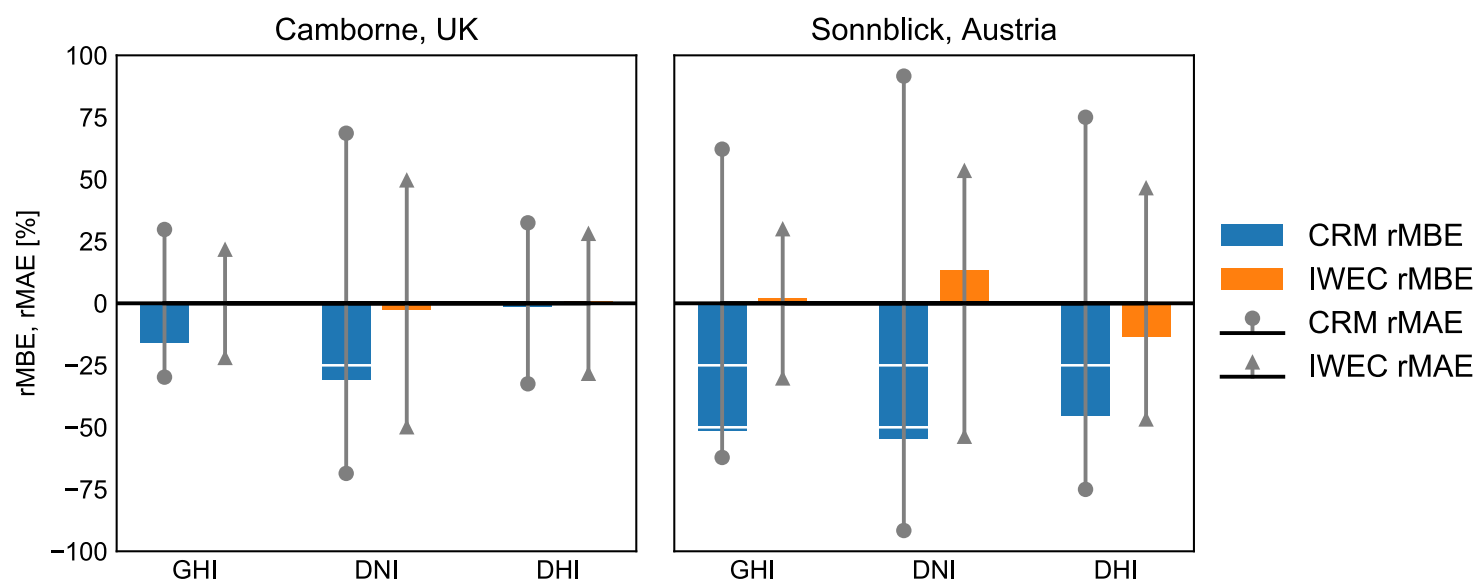

Figure 5: Relative Mean Bias Error (rMBE) and relative Mean Absolute Error (rMAE, mirrored in the negative part of the plots) of the CRM and IWEC models when compared to BSRN measured irradiances. 
is accurately predicted by the CRM model, with the global component performing the best with a coefficient of determination of $r^{2}=0.64$. The direct normal component clearly show the dependence on the cloud cover values expressed in oktas, which causes the horizontal bands that the graph displays. The latter Figure compares BSRN data with irradiances modelled using the IWEC procedure; the prediction are slightly better than those obtained with the CRM, but the correlations still present a significant scatter, in particular when looking at the direct normal component.

The statistical error analysis visualised in Figure 5 and reported in Table 1 confirms that the IWEC model generally performs better than the CRM, and that it is more suited to be applied to different locations as its parameters can be optimised accordingly. The Figure shows relative Mean Bias Error (rMBE) and relative Mean Absolute Error (rMAE) for the two models and for both locations under analysis. Both models are characterised by larger errors for the direct normal component, and by more pronounced errors for Sonnblick data; this could be partly explained by the fact that, for this location, cloud cover data were recorded every three hours rather than one. For the CRM model, the worse predictions obtained for Sonnblick data are also caused by the fact that the model was optimised for British locations, and that the procedure followed to create CIBSE files does not include any parameter calibration that allows the model to adapt to different climates.

Table 1: Relative errors and coefficient of determination for CRM and IWEC solar radiation model when compared to BSRN measured data, expressed as percentage.

\begin{tabular}{llcccccc}
\hline & \multicolumn{3}{c}{ Camborne } & \multicolumn{4}{c}{ Sonnblick } \\
& & GHI & DNI & DHI & GHI & DNI & DHI \\
\hline CRM & rMBE & -16 & -31 & -2 & -51 & -55 & -45 \\
& rMAE & 30 & 69 & 32 & 62 & 92 & 75 \\
& $r^{2}$ & 85 & 54 & 64 & 64 & 53 & 35 \\
\hline \multirow{2}{*}{ IWEC } & rMBE & 0 & -3 & 1 & 2 & 13 & -13 \\
& rMAE & 22 & 50 & 28 & 30 & 54 & 47 \\
& $r^{2}$ & 86 & 61 & 72 & 69 & 57 & 57 \\
\hline
\end{tabular}

The Perez luminous efficacy model was tested against PHE global horizontal illuminance data recorded at Camborne. For Sonnblick there were no measured illuminance data available. As Figure 6 shows, the correlation between measured and modelled data is extremely good, with a coefficient of determination $r^{2}=1.0$. Relative errors were found to be small too, with a $\mathrm{MBE}=-2.3 \%$ and $\mathrm{MAE}=4.4 \%$. Direct normal and diffuse horizontal illuminances were not available for comparison, thus the accuracy of the Perez luminous efficacy model could be evaluated only for global illuminance.

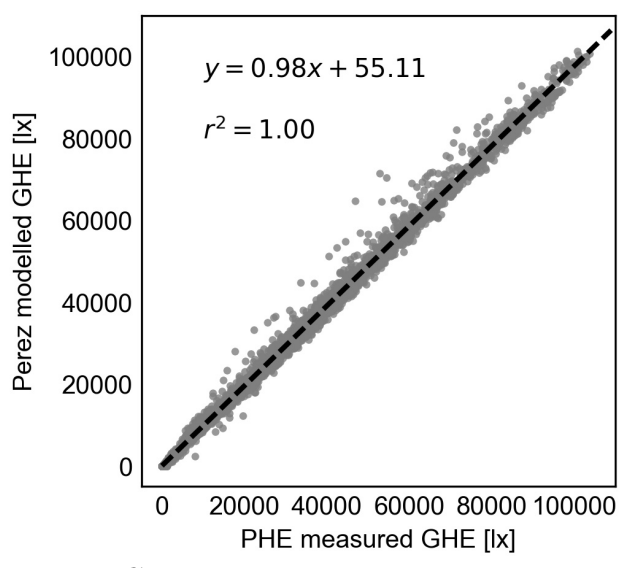

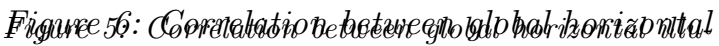

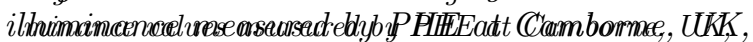

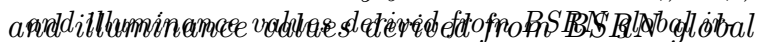

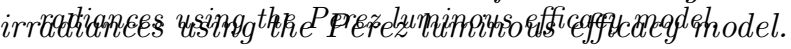

Thevenard, D. J. and A. P. Brunger (2002b). The CBDIMUlBesenlts fatridicMIetenides years for internaThe tional locations Part II Production. ASHRAE the uncertainty that solar radiation models bring to

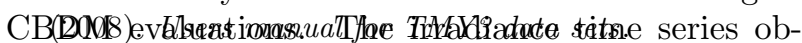
tained from BSRN measurements and from the two models under evaluation - CRM and IWEC - were inserted in .wea climate files for use in annual daylight simulation. Two indoor illuminance profiles were obtained from each simulation: one representing global illuminance at each sensor and at each time step; the other representing only illuminance coming from direct sunlight, also at each sensor and at each time step. From these two profiles, the average illuminance over the working plane at each time step was considered for the error analysis.

In Figure 7 - showing total and direct illuminance values averaged over the working plane, for Sonnblick - it can be noticed that the illuminance results obtained from the IWEC-modelled irradiances performs better than the illuminances obtained from the CRMmodelled series. However, none of the two average illuminance time series correlates well with the reference results from BSRN irradiances. The two models lead to very similar coefficients of determination and the two regression lines seem to indicate a tendency to under-predict average illuminance values within the room. The coefficients of determination found for Camborne (reported in Table 2) are higher than for Sonnblick, and they also show a marked similarity between the two models.

Table 2 reports the errors found when comparing average illuminance obtained with CRM- and IWECderived climate files against BSRN-derived files. Errors for the CRM are larger than those found for the IWEC model, with Sonnblick data resulting in even larger errors than for Camborne. Generally speaking, the error range and ranking are similar to those found for the irradiance values used as input in the 

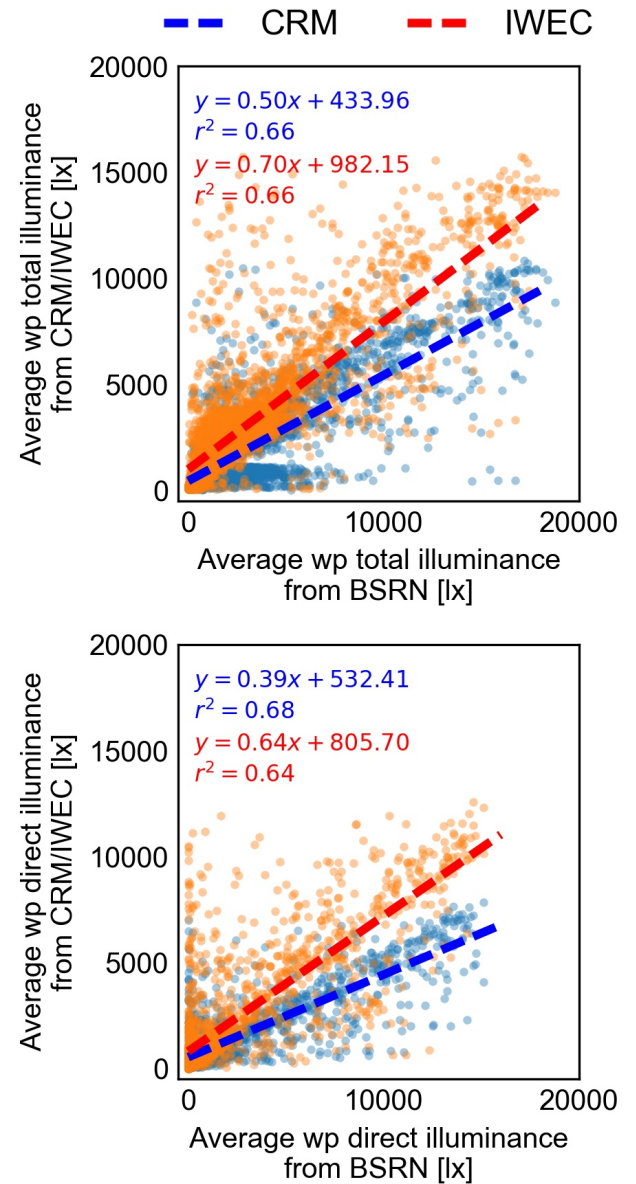

Figure 7: Linear regression analysis of indoor average illuminance values obtained from CRM- and IWEC-modelled irradiance input, compared against average illuminances obtained from BSRN-measured irradiance time series for Sonnblick, Austria. The top plot shows total illuminance, whereas the bottom plot shows direct sunlight illuminance.

simulation (see Table 1), but with rMAEs for direct sunlight illuminance increasing from those observed for the direct normal irradiance component.

From the total and direct illuminance profiles, CBDM metrics were calculated and the results corresponding to different solar radiation models were compared. When looking at CBDM metrics, visualised in Figure 8 , it can be observed that DA and TAI results are consistent with the errors found for the illuminance profiles, i.e. the use of CRM led to an under-prediction of the daylight performance, whereas the IWEC model resulted in a slight over-prediction, compared to reference BSRN-derived values. For Sonnblick, the higher proportion of low illuminance values when using the CRM is signalled by UDI-s values, which reach $10 \%$ for CRM and only $3 \%$ for IWEC, compared to the reference value of $5 \%$. UDI-a results are not significantly affected by changes in solar radiation models, although differences can be found when looking at other UDI ranges. The behaviour of ASE is the most unex-
Table 2: Relative errors and coefficients of determination for indoor average illuminance simulated with irradiances derived from the CRM and IWEC solar radiation models.

\begin{tabular}{llcccc}
\hline & & $\begin{array}{c}\text { Camborne } \\
\text { Total }\end{array}$ & Direct & $\begin{array}{c}\text { Sonnblick } \\
\text { Total }\end{array}$ & Direct \\
\hline CRM & rMBE & -8 & -35 & -54 & -79 \\
& rMAE & 34 & 72 & 70 & 108 \\
& $r^{2}$ & 77 & 62 & 66 & 68 \\
\hline \multirow{2}{*}{ IWEC } & rMBE & 6 & 3 & 4 & 0 \\
& rMAE & 29 & 51 & 35 & 54 \\
& $r^{2}$ & 78 & 64 & 66 & 64 \\
\hline
\end{tabular}

pected one, with both CRM- and IWEC-derived results significantly over-predicting values obtained by using BSRN measurements. This is counter-intuitive, as the errors associated with direct normal irradiance and with direct sunlight illuminance - the only light component contributing towards ASE values - would indicate a significant under-prediction for the CRM and a slight over-prediction by the IWEC model. However, looking at the bottom plot of Figure 7, it can be noticed that there are many instances where BSRN values are very close to zero, whereas CRM and IWEC results reach values over 10,000 lx. This is likely to be the cause of the difference in ASE results; there are several instances throughout the year when direct illuminances obtained from the BSRN series did not exceed the ASE threshold of $1000 \mathrm{~lx}$, whilst CRM and IWEC series led to illuminances higher than $1000 \mathrm{~lx}$, which were therefore accounted for in the ASE calculation.

Table 3 summarises the mean errors characterising CBDM metrics when obtained from either the CRM or the IWEC solar radiation models. The errors are averaged between those found for the two locations under analysis, but they cannot be generalised for other locations.

\section{Conclusion}

The study presented in this paper evaluated the effect that solar radiation models have on CBDM results. Climate files commonly used in simulation rely on such models to derive irradiance and illuminance values from more widely available weather measurements.

Findings showed that the model used within CIBSE TRYs (CRM) results in an under-prediction of solar irradiance, in particular its direct normal component ( $\mathrm{rMBE}=-31 \%$ for UK climates). The models contained in IWEC files resulted in better estimates and were applicable to both locations under evaluation (rMBE within $\pm 3 \%$ for Camborne, UK, and within $\pm 13 \%$ for Sonnblick, Austria). This is an advantage generated by the optimisation of the site-specific parameters specified in the cloudy sky model, as recommended by the creators of the IWEC procedure. 

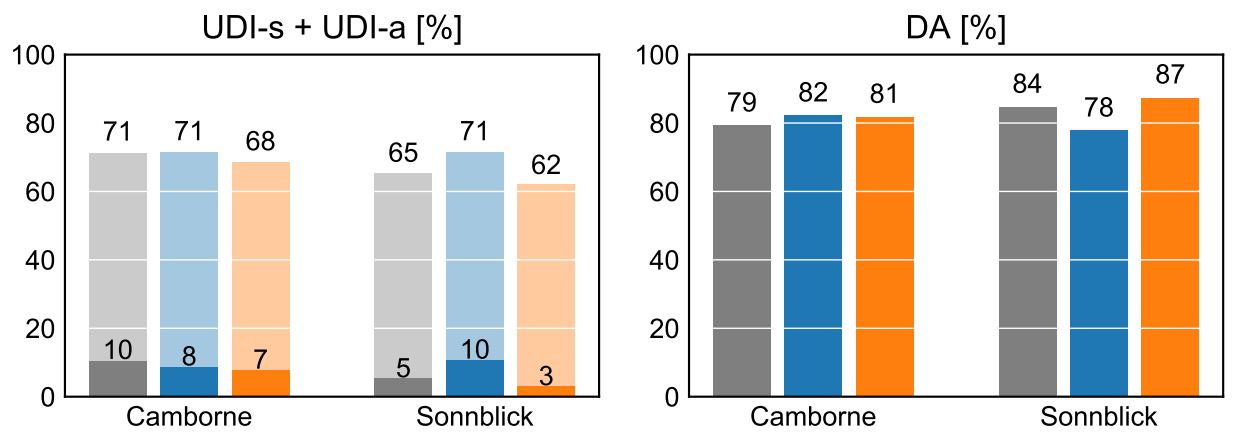

BSRN

TAl [klx hr]

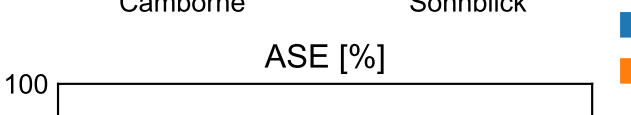

CRM
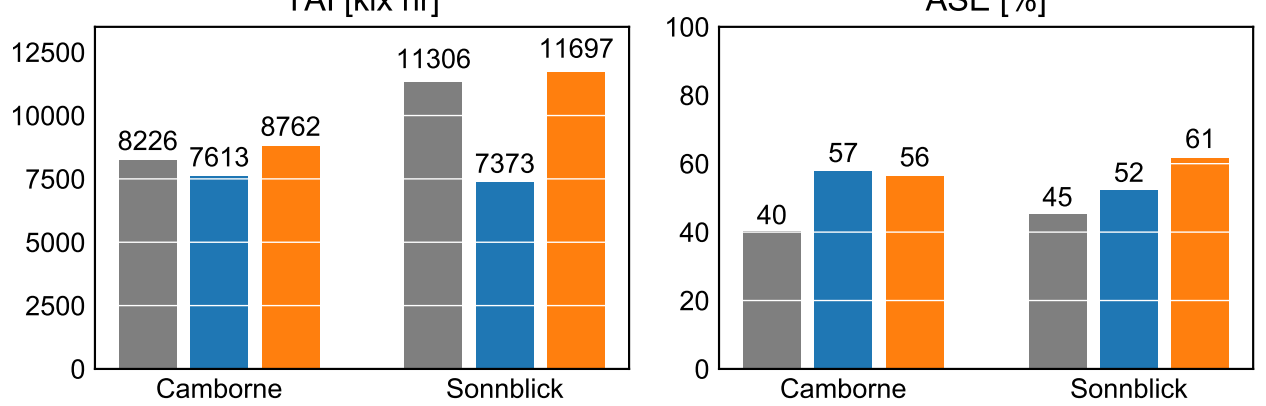

IWEC

Figure 8: CBDM metrics obtained for the two locations under analysis, Camborne and Sonnblick. The metrics were calculated from three different illuminance profiles: the reference one was obtained by using measured irradiances from BSRN as input of the CBDM simulation; the other two were obtained by using irradiances derived from the CRM and IWEC models.

Table 3: rMBE for average indoor illuminance (total and direct) and for CBDM metrics when using different solar radiation models (averages between the two analysed locations). Values are expressed as percentage.

\begin{tabular}{lccccccccc}
\hline & ill $_{\text {avg }}$ & ill_dir $_{\text {avg }}$ & TAI & DA & ASE & UDI-n & UDI-s & UDI-a & UDI-x \\
\hline CRM & -30.6 & -56.8 & -21.1 & -2.1 & 29.0 & 4.5 & 39.6 & 2.2 & -12.6 \\
IWEC & 4.9 & 1.7 & 4.5 & 3.1 & 37.9 & -1.4 & -33.2 & -1.0 & 14.2 \\
\hline
\end{tabular}

However, this solution might not always be possible, if there are not reliable sources of irradiation measurements at the site of interest. Additionally, Thevenard and Brunger (2002b) reported issues with the performance of the IWEC model for tropical locations, that were not investigated in this study and that could result in erroneous CBDM evaluations. More locations and climatic characteristics will be considered in future studies to test the scalability of the findings from the present work.

The Perez luminous efficacy model was investigated for a single location: Camborne, UK. The model was found to be highly accurate for hourly measurements, with errors within $\pm 4 \%$ and a coefficient of determination $r^{2}=1$.

In the last part of the analysis, annual indoor illuminance and CBDM metrics were simulated. The errors characterising average illuminances were found to be very similar to those previously obtained for irradiance values. However, differences found in some CBDM metrics were not always in agreement with the deviations in illuminance values, in particular ASE results. ASE was significantly over-predicted when using solar radiation models; in case of evaluations for compliance, this would lead to a higher rate of failing design options. It is worth noticing that ASE was found to be very sensitive to changes in input variables by previous studies (Brembilla et al., 2017), and it is therefore not surprising that solar radiation models had a significant - and unpredictable - effect on this particular metric.

From this study, it can be concluded that the CRM is not adequate to guarantee realistic CBDM evaluations, especially for climates outside the UK, whereas the IWEC model is a more appropriate solution to derive most CBDM metrics, for temperate and cold climates.

\section{Acknowledgement}

The authors acknowledge the support of CIBSE and Loughborough University. They also thank Dr Matt Eames for the information provided on the existing CIBSE climate files. Further acknowledgements go to people and agencies responsible for the measurement networks used in the study: MIDAS data were provided by the UK Met Office; Public Health England kindly supplied data under the Open Government Licence; ISD data were provided by US National 
Oceanic and Atmospheric Administration (NOAA); and BSRN data were kindly provided by the World Radiation Monitoring Center (WRMC).

\section{Nomenclature}

$\mathrm{CC}=$ Cloud Cover

$\mathrm{GHI}_{\mathrm{CL}}=$ Clear Sky Global Horizontal Irradiance $\left[\mathrm{W} / \mathrm{m}^{2}\right]$

GHI $=$ Global Horizontal Irradiance $\left[\mathrm{W} / \mathrm{m}^{2}\right]$

$\mathrm{DNI}=$ Direct Normal Irradiance $\left[\mathrm{W} / \mathrm{m}^{2}\right]$

DHI $=$ Diffuse Horizontal Irradiance $\left[\mathrm{W} / \mathrm{m}^{2}\right]$

$\mathrm{GHE}=$ Global Horizontal Illuminance $[\mathrm{lx}]$

$\mathrm{MBE}=$ Mean Bias Error

MAE $=$ Mean Absolute Error

$\mathrm{rMBE}=$ relative Mean Bias Error [\%]

$\mathrm{rMAE}=$ relative Mean Absolute Error [\%]

$r^{2}=$ coefficient of determination

\section{References}

Barnaby, C. S. and D. B. Crawley (2011). Weather Data. In J. L. Hensen and R. Lamberts (Eds), Build. Perform. Simul. Des. Oper., Chapter 3. Spon Press.

Bellia, L., A. Pedace, and F. Fragliasso (2015, feb). The role of weather data files in Climate-based Daylight Modeling. Sol. Energy 112, 169-182.

Brembilla, E., D. A. Chi Pool, C. J. Hopfe, and J. Mardaljevic (2017, aug). Inter-model Comparison of Five Climate-Based Daylight Modelling Techniques : Redirecting Glazing / Shading Systems. In Proc. 15th IBPSA Conf., San Francisco, CA, USA, pp. 1047-1056. IBPSA.

The Chartered Institution of Building Services Engineers (2015). Environmental Design - CIBSE Guide A.

CIBSE (2016). Weather data sets. https://www.cibse. org/weatherdata. [Online; accessed 18/01/2019].

Copper, J. and A. Sproul (2013, may). Comparative building simulation study utilising measured and estimated solar irradiance for Australian locations. Renew. Energy 53, 86-93.

DOE, U. (n.d.). Energyplus weather data. https: //www.energyplus.net/weather. [Online; accessed $10 / 01 / 2019]$.

Eames, M., A. Ramallo-Gonzalez, and M. Wood (2016, may). An update of the UK's test reference year: The implications of a revised climate on building design. Build. Serv. Eng. Res. Technol. 37(3), 316-333.

Education Funding Agency (2014). EFA Daylight Design Guide Rev02.

Finkelstein, J. M. and R. E. Schafer (1971). Improved Goodness-Of-Fit Tests. Biometrika 58(3), 641-645.

Huang, Y. J., F. Su, D. Seo, and M. Krarti (2014). Development of 3012 IWEC2 weather files for international locations (RP-1477). ASHRAE Trans. 120, 340.

Iversen, A., S. Svendsen, and T. Nielsen (2013, jun). The effect of different weather data sets and their resolution on climate-based daylight modelling. Light. Res. Technol. 45(3), 305-316.
Kasten, F. and G. Czeplak (1980). Solar and terrestrial radiation dependent on the amount and type of cloud. Sol. Energy 24(2), 177-189.

Larson, G. W., R. A. Shakespeare, C. Ehrlich, J. Mardaljevic, and E. Phillips (1998). Rendering with Radiance: the art and science of lighting visualization. San Francisco, CA, USA: Morgan Kaufmann Publishers Inc.

Maxwell, E. L. (1998). METSTAT - The solar radiation model used in the production of the national solar radiation data base (NSRDB). Sol. Energy 62 (4), 263-279.

Met Office (2012). Met Office Integrated Data Archive System (MIDAS) Land and Marine Surface Stations Data (1853-current).

Muneer, T. (2004). Solar Radiation and Daylight Models.

NOAA (n.d.). Integrated surface database (isd). https: //www.ncdc.noaa.gov/cdo-web/datasets/. [Online; accessed 20/12/2018].

Ohmura, A., E. G. Dutton, B. Forgan, C. Fröhlich, H. Gilgen, H. Hegner, A. Heimo, G. König-Langlo, B. McArthur, G. Müller, R. Philipona, R. Pinker, C. H. Whitlock, K. Dehne, and M. Wild (1998). Baseline Surface Radiation Network (BSRN/WCRP): New Precision Radiometry for Climate Research. Bull. Am. Meteorol. Soc. 79(10), 2115-2136.

Perez, R., P. Ineichen, E. L. Maxwell, R. Seals, and A. Zelenka (1991). Dynamic global-to-direct irradiance conversion models. In Proc. Bienn. Congr. Int. Sol. Energy Soc., Denver, CO.

Perez, R., P. Ineichen, R. Seals, J. Michalsky, and R. Stewart (1990). Modeling daylight availability and irradiance components from direct and global irradiance. Sol. Energy 44(5), 271-289.

Perez, R., R. Seals, and J. Michalsky (1993, mar). All-weather model for sky luminance distributionPreliminary configuration and validation. Sol. Energy 50(3), 235-245.

PHE (n.d.). Public Health England Solar Monitoring Network. https://uk-air.defra.gov.uk/ research/ozone-uv/uv-uk-monitoring. [Online; accessed 07/11/2018].

Thevenard, D. and A. Brunger (2001). Typical weather years for international locations. ASHRAE Res. Proj..

Thevenard, D. J. and A. P. Brunger (2002a). The development of typical weather years for international locations: Part I, algorithms. ASHRAE Trans. 108 PART 2, 376-383.

Thevenard, D. J. and A. P. Brunger (2002b). The development of typical weather years for international locations: Part II, Production. ASHRAE Trans. 108 PART 2(4596), 376-383.

USGBC (2013). LEED Reference Guide for Building Design and Construction, LEED V4.

Wilcox, S. and W. Marion (2008). Users manual for TMY3 data sets. Natl. Renew. Energy Lab. (Technical Report NREL/TP-581-43156). 